\title{
Editorial
}

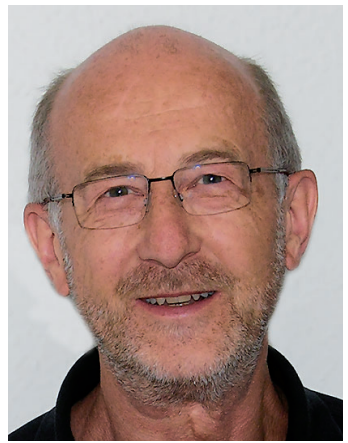

\section{Ein lachendes und ein weinendes Auge}

"Nichts ist beständiger als der Wandel" ... man sagt, dieser weise Spruch habe seine Wurzeln bei HERAKLIT. Vor mehr als 20 Jahren gegründet, geben wir unsere Fachzeitschrift nun in neue Hände. Ab dem kommenden Jahr 2010 wird die "Schweizerische Zeitschrift für GanzheitsMedizin / Swiss Journal for Integrative Medicine" im renommierten und international tätigen Wissenschaftsverlag S. KARGER erscheinen.

Ein lachendes Auge ...

... weil wir davon überzeugt sind, dass der seit 1989 von stetig wachsendem Erfolg begleitete Weg unserer Fachzeitschrift für die Zukunft sichergestellt ist.

Ein weinendes Auge ...

... weil wir eine über viele Jahre ausgeübte erfolgreiche, kreative und immer wieder aufregende Tätigkeit beenden, die uns stets viel Freude bereitet hat.

... weil wir all die Menschen, mit denen wir durch unsere Arbeit freundschaftlich verbunden waren, die uns unterstützt und Mut zugesprochen haben und mit denen wir viele angenehme Stunden verbringen durften, nun nicht mehr so häufig sehen werden.

... weil man einer interessanten Lebensphase mit ihren schönen Erinnerungen einfach ein wenig nachtrauern muss.

Verlag und Redaktion bedanken und verabschieden sich heute bei Ihnen allen, denen wir mit den Früchten unserer Arbeit eine Freude bereiten konnten, die uns über die vielen Jahre freundschaftlich verbunden waren, die uns unterstützt haben und uns mit Rat und Tat beigestanden sind.

Dr.rer.nat. Stefan R. Becker

Gründer und Herausgeber "Schweizerische Zeitschrift für GanzheitsMedizin" (1989-2009) 